\title{
Responses of Female Yellow Warblers to Playbacks Signaling Brood Parasitism or Predation Risk: A Quasi- Replication Study
}

\author{
Shelby L. Lawson", ${ }^{1, *}$ Janice K. Enos ${ }^{1}$, Niko C. Mendes ${ }^{1}$, Sharon A. Gill ${ }^{2}$, and Mark E. Hauber ${ }^{1}$ \\ ${ }^{1}$ Department of Evolution, Ecology, and Behavior, School of Integrative Biology, University of Illinois at Urbana-Champaign, \\ ${ }^{2}$ Department of Biological Sciences, Western Michigan University, Kalamazoo, Michigan \\ *Corresponding author (Email: slawson3@illinois.edu)
}

Citation - Lawson, S. L., Enos, J. K., Mendes, N. C., Gill, S. A., \& Hauber, M. E. (2021). Responses of female yellow warblers to playbacks signaling brood parasitism or predation risk: A quasi-replication study. Animal Behavior and Cognition, 8(2), 216-230. https://doi.org/10.26451/abc.08.02.08.2021

\begin{abstract}
Many avian species are negatively impacted by obligate avian brood parasites, which lay their eggs in the nests of host species. The yellow warbler (Setophaga petechia), which is host to the brood-parasitic brownheaded cowbird (Molothrus ater), represents one of the best-replicated study systems assessing antiparasitic host defenses. Over 15 prior studies on yellow warblers have used model-presentation experiments, whereby breeding hosts are exposed to models of brown-headed cowbirds or other nest threats, to test for anti-parasitic defenses unique to this species. Here we present results from our own quasi-replication study of the yellow warbler/brownheaded cowbird system, which used a novel design compared to previous experiments by pivoting to conduct acoustic playback treatments only, rather than presenting visual models with or without calls. We exposed active yellow warbler nests to playbacks of brown-headed cowbird chatters (brood parasite), blue jay (Cyanocitta cristata; nest predator) calls, conspecific "seet" calls (a referential alarm call for brood parasitism risk), conspecific "chip" calls (a generic alarm call), or control wood thrush (Hylocichla mustelina; harmless heterospecific) songs during the incubation stage. Similar to previous studies, we found that female yellow warblers seet called more frequently in response to playbacks of both brood parasitic chatter calls and conspecific seet calls whereas they produced more chip calls in response to the playback of nest predator calls. In contrast, female yellow warblers approached all playbacks to similar distances, which was different from the proximity patterns seen in previous studies. Our study demonstrates the importance of both replicating, and also pivoting, experimental studies on nest defense behaviors, as differences in experimental design can elicit novel behavioral response patterns in the same species.
\end{abstract}

Keywords - Alarm calling, Antiparasitic defenses, Brood parasitism, Host-parasite interactions, Nest-protection, Playback presentations, Referential alarm call

The fitness of over 200 North American passerine species is known to be negatively impacted by the brown-headed cowbird (Molothrus ater, hereafter "cowbird"), an obligate avian brood parasite that lays its eggs in the nests of other species, leaving the host to care for the parasitic young (Davies, 2010). The behavioral defenses that hosts use to prevent costly cowbird parasitism have been well-studied using similar experimental design paradigms: typically, the host is exposed to stimuli representing this brood parasite and procedural controls, and the host's behavioral responses are compared across treatments (e.g., Briskie et al., 1992; Robertson \& Norman, 1976a; Sealy et al., 1998).

The yellow warbler (Setophaga petechia), a common host for cowbirds, represents one of the best replicated study systems assessing behavioral defenses related to host-parasite interactions (see Appendix for summary). This is perhaps because yellow warblers have a unique, referential anti-cowbird call, 
known as the seet call, that they use to warn conspecifics of nearby female parasites (Gill, Grieef et al., 1997; Gill, Neudorf et al., 1997; Gill \& Sealy, 2004; Hobson \& Sealy, 1989a). The seet call is produced by both males and female warblers in response to cowbirds, and females that hear this call rush back to sit on their nests to presumably prevent cowbirds from inspecting and parasitizing the nest (Gill, Neudorf et al., 1997; Gill \& Sealy, 2004). The use of the seet call is strikingly different from the yellow warbler's "chip" call, a general alarm call used to warn of a range of threats, such as predators and intruding conspecifics (Gill \& Sealy, 1996; Hobson et al., 1988). The duality of these two alarm call types and the differing socioecological contexts under which they are produced have led to a plethora of experimental studies in the yellow warbler system, both from the same research groups and across different institutions, each study addressing similar questions regarding the seet call, while simultaneously pivoting to add new details of biological knowledge to the system (see Appendix). As such, the cues for and the function of the referential seet calls in yellow warblers may already represent one of the best replicated behavioral, ecological, and cognitive systems in a wild songbird species, while also providing new opportunities to both replicate and pivot from some of the most robust findings in this system.

Several early studies on yellow warbler antiparasitic nest defenses noted aggressive responses from both sexes towards models (in particular, of adult females) of brown-headed cowbirds presented to host pairs at the nest, given that female cowbirds represent the most immediate brood parasitic threat for foreign-egg laying (Folkers \& Lowther, 1985; Robertson \& Norman, 1976a, b). This experimental approach was then expanded by studies that tested yellow warblers' responses to female cowbird models during different stages of nesting and found that aggression was stronger during laying and incubation (relative to the nestling stage), when hosts are at the highest risks of being successfully parasitized (Burgham \& Picman, 1989; Hobson \& Sealy, 1989a). In turn, a series of studies by Gill and Sealy characterized how yellow warblers produced seet calls specifically in response to cowbirds, and that this functionally referent response was produced largely during laying and incubation as seen in previous studies examining shifts in behavioral aggression across the nesting stages (Gill et al., 2008; Gill, Grieef, et al., 1997; Gill, Neudorf et al., 1997; Gill \& Sealy, 1996, 2003, 2004). Additional replication and pivoting studies were conducted that added comparisons between different nest threat types of models (brood parasite versus nest predator; Burgham \& Picman, 1989; Campobello \& Sealy, 2011; Gill, Neudorf, et al., 1997; Gill \& Sealy, 1996, 2004; Guigueno \& Sealy, 2011; Kuehn et al., 2016), stimulus sensory modality (visual model and acoustic playback; Campobello \& Sealy, 2011; Gill, Neudorf, et al., 1997; Gill \& Sealy, 2004; Kelly et al., 2019), and geographic overlap with cowbirds (sympatry versus allopatry; Briskie et al., 1992; Gill \& Sealy, 2004; Kuehn et al., 2016) (see Appendix). Taken together, these studies support that seet calls are specifically associated with the presence of the female brood parasite and mainly produced when cowbirds pose an active threat to the nest, whereas chips are produced in response to other types of threats.

Here we conducted our own quasi-replication study in the yellow warbler/brown-headed cowbird system using acoustic presentations as our sole experimental stimuli. We present a novel, playback-only based experimental design to probe anti-parasitic responses of female (this study) and male yellow warblers (Lawson et al., 2021), as well as heterospecific red-winged blackbirds (Agelaius phoeniceus, Lawson et al., 2020). Accordingly, during laying/incubating stages at yellow warbler nests, we presented playbacks of female cowbird chatters, conspecific seet calls, conspecific chip calls, nest predator calls (blue jay, Cyanocitta cristata), as well as procedural controls of songs of a harmless sympatric heterospecific, the wood thrush (Hylocichla mustelina). We then compared behavioral responses of female yellow warblers across treatments. There is also novelty in our quasi-replication in that we applied acoustic stimuli alone for the full series of playbacks. We predicted that female warblers would 1) produce seet calls exclusively in response to cowbird chatter and seet call playbacks, 2) produce more chip calls in response to blue jay calls compared to other playbacks, and 3) respond more quickly and approach all playbacks more closely than the control wood thrush playback. 


\section{Method}

\section{Sites and Study Species}

The experiment was conducted at multiple wetland sites in Champaign $(n=3)$, Iroquois $(n=1)$, and Vermillion counties $(n=3)$ in central Illinois, USA, where yellow warblers commonly serve as hosts to cowbird parasitism (Kelly et al., 2019; Lawson et al., 2020; Merrill et al., 2017). Sites were comprised of mesic shrubland habitat, with dominant shrubs including willow (Salix spp.), dogwood (Cornus spp.), and autumn olive (Elaeagnus umbellate) (Kelly, 2017; Kelly et al., 2018; Lawson et al., 2020). Yellow warblers are neotropical migrants that arrive at our sites in late-April and breed from early-May through late-June, with a peak and synchronous period of breeding during mid-to-late-May (Kelly et al., 2019, Lawson et al., 2020).

These studies were approved by the animal ethics committee (IACUC) of the University of Illinois (\#17259), and by USA federal (MB08861A-3) and Illinois state agencies (NH19.6279).

\section{Playback Stimulus Construction}

Playback files and methodology for this experiment follow those from another playback experiment conducted in the same yellow warbler population (Lawson et al., 2020). In short, we created playlists for five different playback treatments: (1) female cowbird chatters, (2) conspecific seet calls, (3) conspecific chip calls, (4) blue jay calls, and (5) wood thrush songs.

Audio files were obtained from Xeno-Canto (Blackburn et al., 2014), all sourced from the Midwestern United States (Illinois, Michigan, Minnesota, and Ohio), except for seet calls, which were sourced from Manitoba, Canada, by Gill and Sealy (2003). Playlists were created using Adobe Audition CC 2018. To minimize signal-to-noise ratio, frequencies below $500 \mathrm{~Hz}$, which are well lower than the range of any of our call stimuli, were filtered out. Vocalizations from at least three different individuals comprised each playlist exemplar in a random order and then repeated to create the 10-minute playlist. To further reduce pseudoreplication (Kroodsma et al., 2001), we constructed five different files per playback type, and chose one exemplar file randomly for each trial (described below). Intervals of silence were inserted between vocalizations, ranging from two to six seconds based on rates found in natural recordings on Xeno-Canto. Playbacks were broadcast at $\sim 90 \mathrm{~dB}$ SPL (measured $0.5 \mathrm{~m}$ from speaker).

Playbacks were presented from an AYL-SoundFit speaker connected to a Samsung Galaxy 8 cellular phone loaded with the audio files. We placed the speaker $\sim 1 \mathrm{~m}$ high in vegetation and recorded data from > $10 \mathrm{~m}$ away. Each playback trial lasted for $10 \mathrm{~min}$.

\section{Determining the Nesting Status of Females Hosts}

We conducted playback trials on active yellow warbler territories with sighted females between mid-May and late-June in 2018 and 2019. We first systematically visited each site twice weekly, two to three days apart, to search for actively singing males with a female on the territory. During the visits we followed each male at the site for $10 \mathrm{~min}$ and noted any mate-guarding. Mate-guarding is a behavior commonly used to assign pairing status in parulid (wood) warblers, where males closely follow their mate while she is laying (yellow warblers: Hobson \& Sealy 1989b; other parulid warblers: Chuang-Dobbs et al., 2001; Stutchbury et al., 1994; Toms, 2012). We also searched the territories (within $30 \mathrm{~m}$ of male's song perch; Kelly et al. 2018) for active nests and/or females exhibiting nest defense behaviors (e.g., alarm-calling, perch-switching, wing-flicking, circle-flight), which have been used to assign pairing status in similar studies (Ficken \& Ficken, 1965; Hobson \& Sealy, 1989b; Marshall \& Balda, 1974; Mitra, 1999).

We tested a female if we observed mate-guarding by the male and/or evidence of an active nest at least two visits in a row. Furthermore, females were assessed only if their nest was in the laying or incubation stage, when these warblers are most likely to give seet calls (Gill et al., 2008, Gill \& Sealy 
1996). We verified nest stage prior to trials by checking on known nests to confirm their content, or if the nest location was unknown, by observing females for signs of incubation/laying but not of the other nesting stages (e.g., carrying nesting material, carrying food for nestlings or fledglings, etc.).

\section{Playback Trials}

Playbacks occurred between 0500 and $1200 \mathrm{hr}$ local time. Because we did not band territorial birds for individual identification, we tested nests that were $\geq 30 \mathrm{~m}$ apart to attain biological independence. Nests at this distance likely belonged to different breeding units based on average territory size of yellow warblers (DellaSala, 1986; Kendeigh, 1941), including those breeding in Illinois (Kelly et al., 2018). We also waited 30-60 min between playbacks at neighboring sites to avoid any carryover effects on individuals in the proximity (Lawson et al., 2020).

Within the mostly agricultural landscape of Central Illinois, the number of breeding female yellow warblers at our study sites was limited and so, to increase sample sizes, female subjects were tested again with a second, different playback type. We allowed $24-72 \mathrm{hrs}($ mean $=47.1)$ between trials to avoid habituation, and used another, randomly assigned treatment to minimize order effects. Nonetheless, we still included order as a fixed predictor in our statistical models (see below).

If a nest location was known, the speaker was placed 5-6 m from the nest; otherwise, the playback speaker was placed 5-6 $\mathrm{m}$ from the male's most commonly used song post. During the playback trials, we recorded the female's behavioral responses, as follows, within $30 \mathrm{~m}$ of the speaker: (1) response latency (seconds after the start of trial when a switch to aggressive behaviors occurred: posturing, hopping, alarm calling, or attacking the speaker); (2) number of seets; (3) number of chips; and (4) closest approach to the speaker (meters). On territories where nest location was known, we also recorded whether females returned to sit on and protect their nests after hearing or producing seet calls. Thirteen females/sites could not be retested with a second playback ( $n=6$ in 2018, $n=7$ in 2019) either because their nests were depredated between trials or because they were not present for the second trial.

\section{Statistical Analyses}

We evaluated whether playback treatment affected the four behavioral response variables collected (latency, number of seets, number of chips, and closest approach) using separate general linear models for each. All models included playback treatment, year (2018 or 2019), date (ordinal days after start of season - May $1^{\text {st }}$ ), and trial order (first or second, to account for repeated playbacks at the same site) as fixed effects. For three of the variables (latency, number of seets and number of chips), there were a large number of biologically relevant non-responses (i.e., subject never responded or produced no vocalizations). As such, these variables were first analyzed using zero-inflated negative binomial models, which analyze the data as a binomial variable (response versus no response) to determine whether nonresponses were more common depending on the treatment. We then separately analyzed only data where females had responded (<600 seconds latency, seet called, and/or chip called) to determine whether the magnitude of the responses (seconds of latency or the number of seet/chip calls) varied between treatments. For this second set of models (responses only) we analyzed the latency and seet data using a general linear model with a Poisson fit and log-e (ln) transformed the chip data to fit a normal distribution and ran a linear model. Lastly, we log-e (ln) transformed the closest approach data to fit a normal distribution and ran a linear model.

We also evaluated whether females with known nest locations were more likely to return to the nest quickly after hearing or producing seet calls, using two separate general linear models with a binomial fit; the first one to test female return within one minute of playback, and the second one to test female return within 3 min.

All statistical tests were conducted in the statistical program R 3.5.2 (packages lme4, nlme, multcomp, emmeans and car), with $\alpha=.05$. For all significant models we ran post hoc tests with a Tukey 
correction to compare the least-square means outputs between playback treatments and provided $z$-scores and $95 \%$ confidence intervals as measures of effect size.

\section{Results}

We conducted 84 total playback trials at $n=49$ nest locations, that included cowbird chatters $(n=$ $20)$, Yellow warbler seet calls $(n=16)$, Yellow warbler chip calls $(n=15)$, Blue jay calls $(n=13)$, and Wood thrush songs $(n=20)$.

\section{Response and its Latency}

Based on the binomial model, female yellow warblers differed in whether they responded to playbacks depending on treatment (treatment term: $F(4,83)=7.27, p<.001$; Figure 1). There was no significant effect of year (year term: $F(1,83)=1.39, p=.24$; estimate $=2.85,95 \%$ CI $[0.6,16.2]$ ), date $($ date term: $F(1,83)=0.51, p=.47$; estimate $=1.02,95 \%$ CI $[0.9,1.1])$, or trial order $($ trial term: $F(1,83)$ $=0.89, p=.34$; estimate $=2.2,95 \%$ CI $[0.5,12.4])$ on whether females responded to the playbacks. Based on post hoc pairwise comparisons, female warblers were less likely to respond to control wood thrush playbacks compared to cowbird chatters $(z=-3.29, p=.008)$, blue jay calls $(z=-2.71, p=.04)$, chips $(z=$ $-2.84, p=.03)$, and seets $(z=-3.09, p=.01)$. All pairwise comparisons between non-control treatments were not significant (Table 1$)$.

When we compared latencies of warblers who responded to the treatment playbacks (latency < $600 \mathrm{~s}$ ), we found no significant differences in how long warblers took to respond across treatments (treatment term: $F(4,65)=2.37, p=.062$ ), year (year term: $F(1,65)=.04, p=.84$; estimate $=0.93,95 \%$ CI $[0.8,0.9]$ ), date (date term: $F(1,65)=1.29, p=.259$; estimate $=1.01,95 \%$ CI $[1.0,1.0])$, or trial (trial term: $F(1,65)=1.79, p=.185$; estimate $=1.6,95 \%$ CI $[1.5,1.7])$.

Figure 1

Latency of Female Yellow Warblers to Respond to Each Playback Treatment

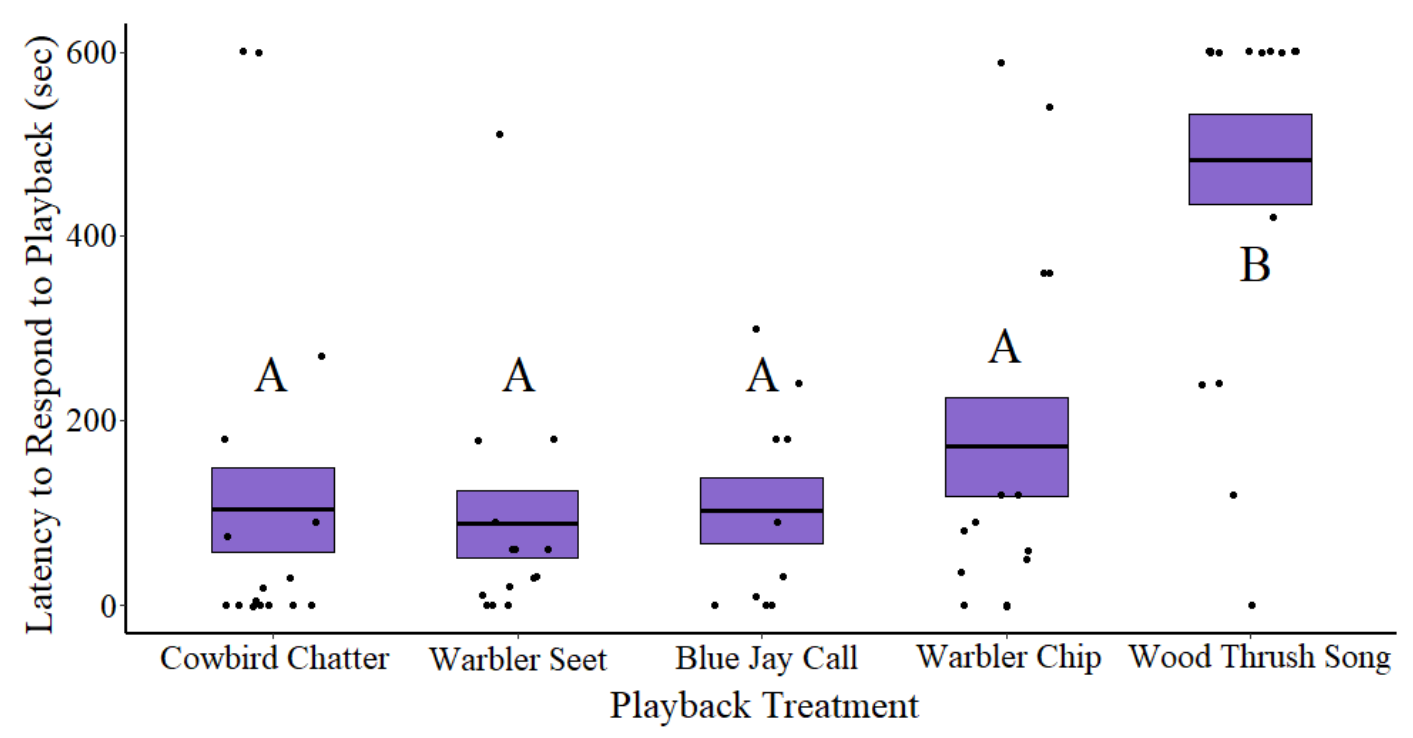

Note. Means are shown with the bold line, and shaded boxes represent standard errors. Boxes with different letters denote post hoc statistical differences between treatments in the binomial model. 
Table 1

Pair-wise Comparisons of Latency Data by Treatment

\begin{tabular}{lcccc}
\hline $\begin{array}{l}\text { Comparisons (binomial model of response vs no } \\
\text { response) }\end{array}$ & $z$ ratio & estimate & CI & \multicolumn{2}{c}{$p$ value } \\
\hline BLJA - BHCO & -0.12 & -0.13 & $-2.09-1.83$ & .999 \\
Chip - BHCO & 0.91 & 1.43 & $-0.53-3.39$ & .886 \\
Seet - BHCO & 0.29 & 0.31 & $-1.65-2.27$ & .998 \\
WOTH - BHCO & -3.29 & -2.88 & $4.85-(-.92)$ & $.008^{* *}$ \\
Chip - BLJA & 0.94 & 1.57 & $-0.39-3.53$ & .875 \\
Seet - BLJA & 0.36 & 0.45 & $-1.51-2.41$ & .995 \\
WOTH - BLJA & -2.71 & -2.75 & $-4.71-(-0.79)$ & $.048^{*}$ \\
Seet - Chip & -0.67 & -1.11 & $-3.07-0.85$ & .960 \\
WOTH - Chip & -2.84 & -4.32 & $-6.28-(-2.36)$ & $.033^{*}$ \\
WOTH - Seet & -3.09 & -3.20 & $-5.16-(-1.24)$ & $.015^{*}$ \\
\hline
\end{tabular}

Note. Brown-headed cowbird chatters (BHCO), yellow warbler seets (Seet), yellow warbler chips (Chip), blue jay calls (BLJA), and wood thrush song (WOTH).

Significant post hoc differences are represented with asterisks $(* * * p<.001, * * p<.01, * p<.05)$

\section{Seet Call Production}

Playback treatment (treatment term: $F(4,83)=27.16, p<.001$ ) significantly affected whether female warblers produced any seet calls or not (Figure 2). Neither year (year term: $F(1,83)=3.26, p=$ .07 ; estimate $=2.60,95 \% \mathrm{CI}[0.5,13.4]$ ), date (date term: $F(1,83)=1.21, p=.27$; estimate $=0.97,95 \%$ CI $[0.8,1.0]$ ), nor trial order (trial term: $F(1,83)=1.81, p=.18$; estimate $=0.49,95 \%$ CI $[0.1,2.1]$ ) had a significant effect on whether females produced any seets. Yellow warblers only seet called during cowbird chatter and seet call playbacks. As such, only these playbacks were compared using post hoc pairwise comparisons to every other treatment. Female warblers were more likely to seet during cowbird chatter trials compared to blue jay $(z=2.63, p=.02)$, chip $(z=2.70, p=.01)$, and wood thrush trials $(z=$ $2.89, p=.01$ ) (Table 2). Similarly, female warblers were also more likely to seet in response to seet call playbacks compared to blue jay $(z=2.50, p=.03)$, chip call $(z=2.55, p=.02)$, and wood thrush trials $(z$ $=2.72, p=.01)$. Female warblers were just as likely to produce seets in response to cowbird chatter as seet call playbacks $(z=0.31, p=.94)$. Similarly, when we then compared seet call rates between cowbird chatter and seet call playbacks, we found that female warblers gave seets at equal rates during cowbird chatter playbacks compared to seet playbacks (treatment term: $F(1,21)=1.55, p=.22$ ). Neither year (year term: $F(1,21)=.95, p=.34$; estimate $=0.70,95 \%$ CI $[0.3,1.4])$, date (date term: $F(1,21)=1.43, p$ $=.24$; estimate $=0.97,95 \%$ CI $[0.9,1.0])$, or trial (trial term: $F(1,21)=1.42, p=.24$; estimate $=1.54$, $95 \%$ CI $[0.7,3.2])$ significantly affected seet rate. 
Figure 2

Mean Number of Seets Produced by Female Yellow Warblers in Response to Each Playback Treatment

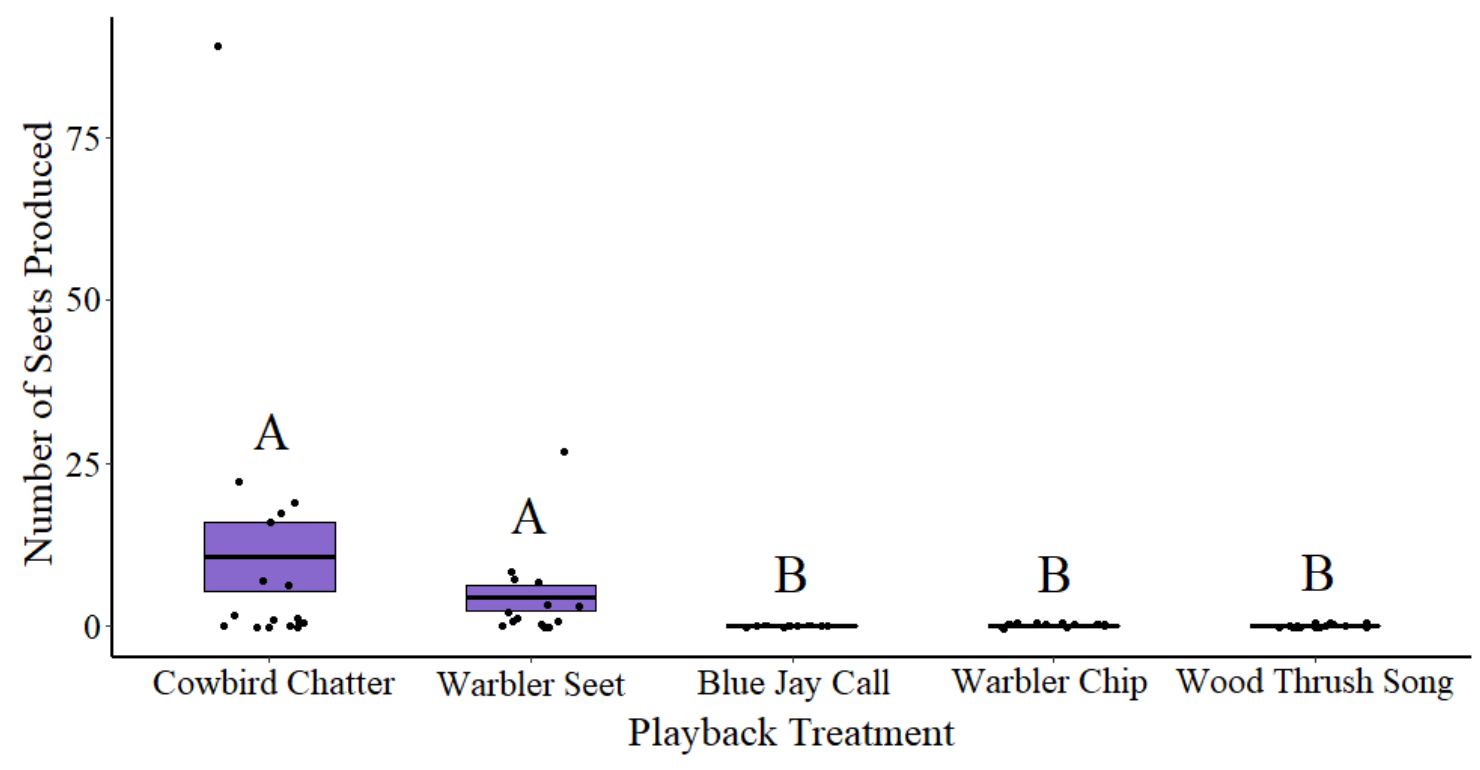

Note. Means are shown with the bold line, and shaded boxes represent standard errors. Boxes with different letters denote post hoc statistical differences between treatments in the binomial model.

Table 2

Pair-Wise Comparisons of Seet Calling Data by Treatment

\begin{tabular}{|c|c|c|c|c|}
\hline Comparisons (binomial model of seet vs no seet) & $z$ ratio & estimate & $\mathrm{CI}$ & $p$ value \\
\hline $\mathrm{BHCO}-$ Seet & 0.31 & 0.22 & $-1.74-2.18$ & .946 \\
\hline BHCO - BLJA & 2.63 & 4.16 & $2.14-6.06$ & $.022 *$ \\
\hline Seet - BLJA & 2.50 & 3.93 & $1.94-5.86$ & $.033 *$ \\
\hline BHCO - Chip & 2.70 & 4.17 & $2.14-6.06$ & $.019 *$ \\
\hline Seet - Chip & 2.55 & 3.94 & $1.94-5.86$ & $.029 *$ \\
\hline $\mathrm{BHCO}-\mathrm{WOTH}$ & 2.89 & 4.28 & $2.24-6.16$ & $.010 *$ \\
\hline Seet - WOTH & 2.72 & 4.05 & $2.04-5.96$ & $.017 *$ \\
\hline
\end{tabular}

Note. Brown-headed cowbird chatters (BHCO), yellow warbler seets (Seet), yellow warbler chips (Chip), blue jay calls (BLJA), and wood thrush song (WOTH).

Significant post hoc differences are represented with asterisks $(* * * p<.001, * * p<.01, * p<.05)$

\section{Chip Production}

Playback treatment (treatment term: $F(4,83)=4.54, p=.002$ ) significantly influenced whether female yellow warblers chipped at all in response to the playbacks (Figure 3). Year of playback was also significant, in that warblers chipped during more trials in 2019 than 2018 (year term: $F(1,83)=4.60, p=$ .03 ; estimate $=3.51,95 \%$ CI $[1.1,11.5])$. Neither playback date nor trial order significantly influenced chip rate (date term: $F(1,83)=2.56, p=.11$; estimate $=0.95,95 \%$ CI $[0.8,1.0]$; trial term: $F(1,83)=$ $0.57, p=.44$; estimate $=1.55,95 \%$ CI $[0.5,4.7])$. With post hoc comparisons we found that blue jay $(z=$ $2.79, p=.03)$ and chip call $(z=3.15, p=.01)$ playbacks were more likely to elicit chips from female warblers than the control wood thrush. All other pairwise comparisons between treatments were nonsignificant (Table 3). We then compared chip call rates of birds who produced any chips during the trial, and found no significant differences between treatments (treatment term: $F(1,83)=2.25, p=.07$ ), year (year term: $F(1,83)=0.14, p=.70$; estimate $=0.15,95 \%$ CI $[-0.6,0.9])$, date $($ date term: $F(1,83)=1.37$, 
$p=.24$; estimate $=-0.02,95 \% \mathrm{CI}[-0.06,0.01])$, or trial $($ trial term: $F(1,83)=2.74, p=.10$; estimate $=$ $0.64,95 \%$ CI $[-1.4,0.1])$.

\section{Figure 3}

Mean Number of Chips Produced by Female Yellow Warblers in Response to Each Playback Treatment

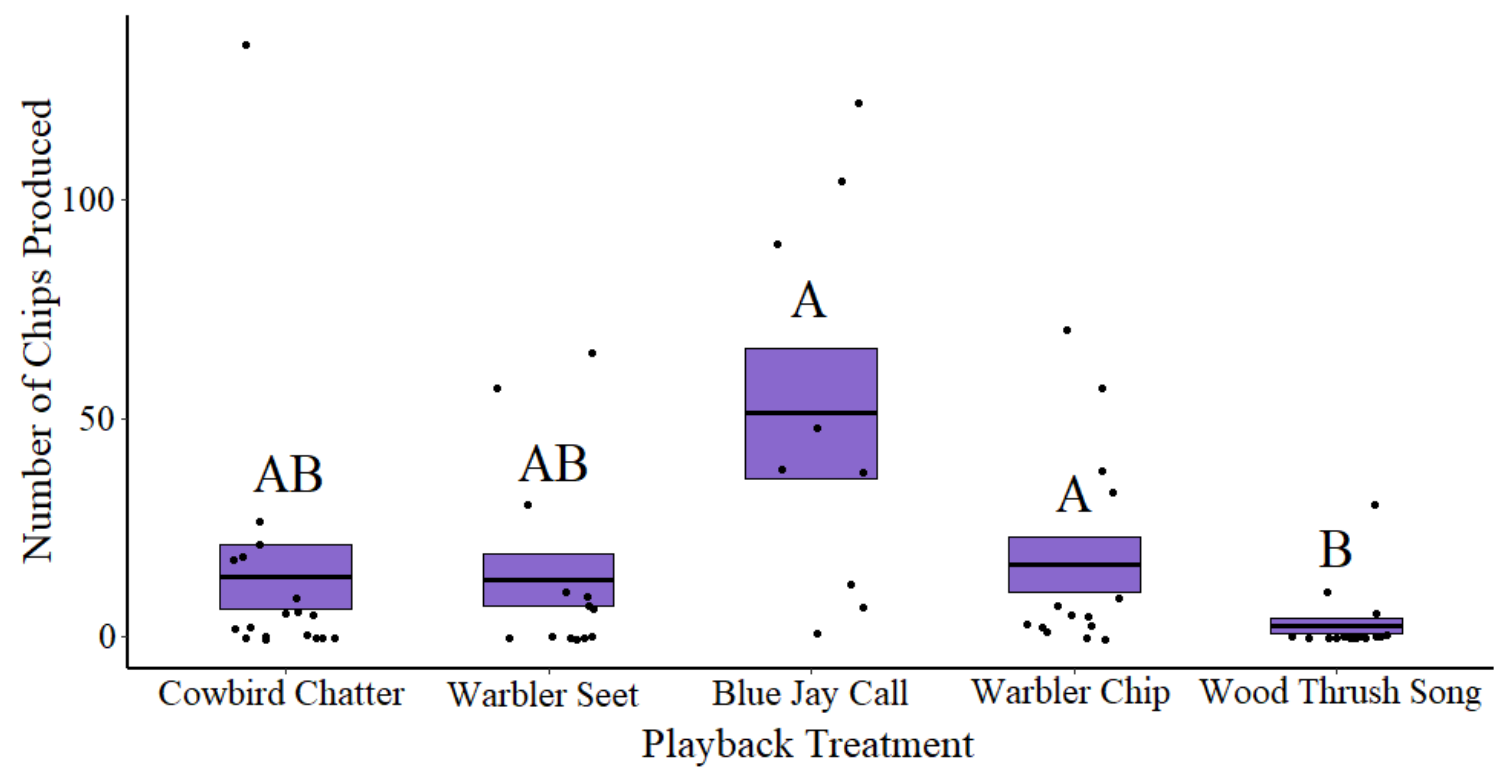

Note. Means are shown with the bold line, and shaded boxes represent standard errors. Boxes with different letters denote post hoc statistical differences between treatments in the binomial model.

Table 3

Pair-Wise Comparisons of Chip Call Data by Treatment

\begin{tabular}{|c|c|c|c|c|}
\hline Comparisons (binomial model of chip vs no chip) & $z$ ratio & estimate & CI & $p$ value \\
\hline $\mathrm{BLJA}-\mathrm{BHCO}$ & 1.51 & 1.77 & $-0.19-3.73$ & .545 \\
\hline Chip - BHCO & 1.65 & 1.54 & $-0.42-3.50$ & .453 \\
\hline Seet - BHCO & -0.77 & -0.57 & $-2.53-1.39$ & .935 \\
\hline WOTH - BHCO & -2.09 & -1.55 & $-3.51-0.41$ & .214 \\
\hline Chip - BLJA & -0.17 & -0.23 & $-2.19-1.73$ & .999 \\
\hline Seet - BLJA & -1.94 & -2.35 & $-4.31-0.39$ & .284 \\
\hline WOTH - BLJA & -2.79 & -3.33 & $-5.29-1.37$ & $.039 *$ \\
\hline Seet - Chip & -2.14 & -2.11 & $-4.07-0.15$ & .192 \\
\hline WOTH - Chip & -3.15 & -3.09 & $-5.05-1.13$ & $.013 *$ \\
\hline WOTH - Seet & -1.25 & -0.98 & $-2.94-0.98$ & .712 \\
\hline
\end{tabular}

Note. Brown-headed cowbird chatters (BHCO), yellow warbler seets (Seet), yellow warbler chips (Chip), blue jay calls (BLJA), and wood thrush song (WOTH). Significant post hoc differences are represented with asterisks $(* * * p<.001, * * p<.01, * p<$ $.05)$

\section{Closest Approach}

Closest approach was not significantly affected by treatment (treatment term: $F(4,83)=2.15, p=$ .08 ), year (year term: $F(1,83)<0.01, p=.92$; estimate $=-0.01,95 \%$ CI $[-0.3,0.3]$ ), date (date term: $F(1$, $83)=0.03, p=.86$; estimate $=0.001,95 \%$ CI $[-0.01,0.02])$, or trial order (trial term: $F(1,83)=1.03, p=$ .31 ; estimate $=1.8,95 \%$ CI $[-0.1,0.5])$ (Figure 4$)$. 
Figure 4

Mean Closest Approach to Speaker by Female Yellow Warblers for Each Playback Treatment

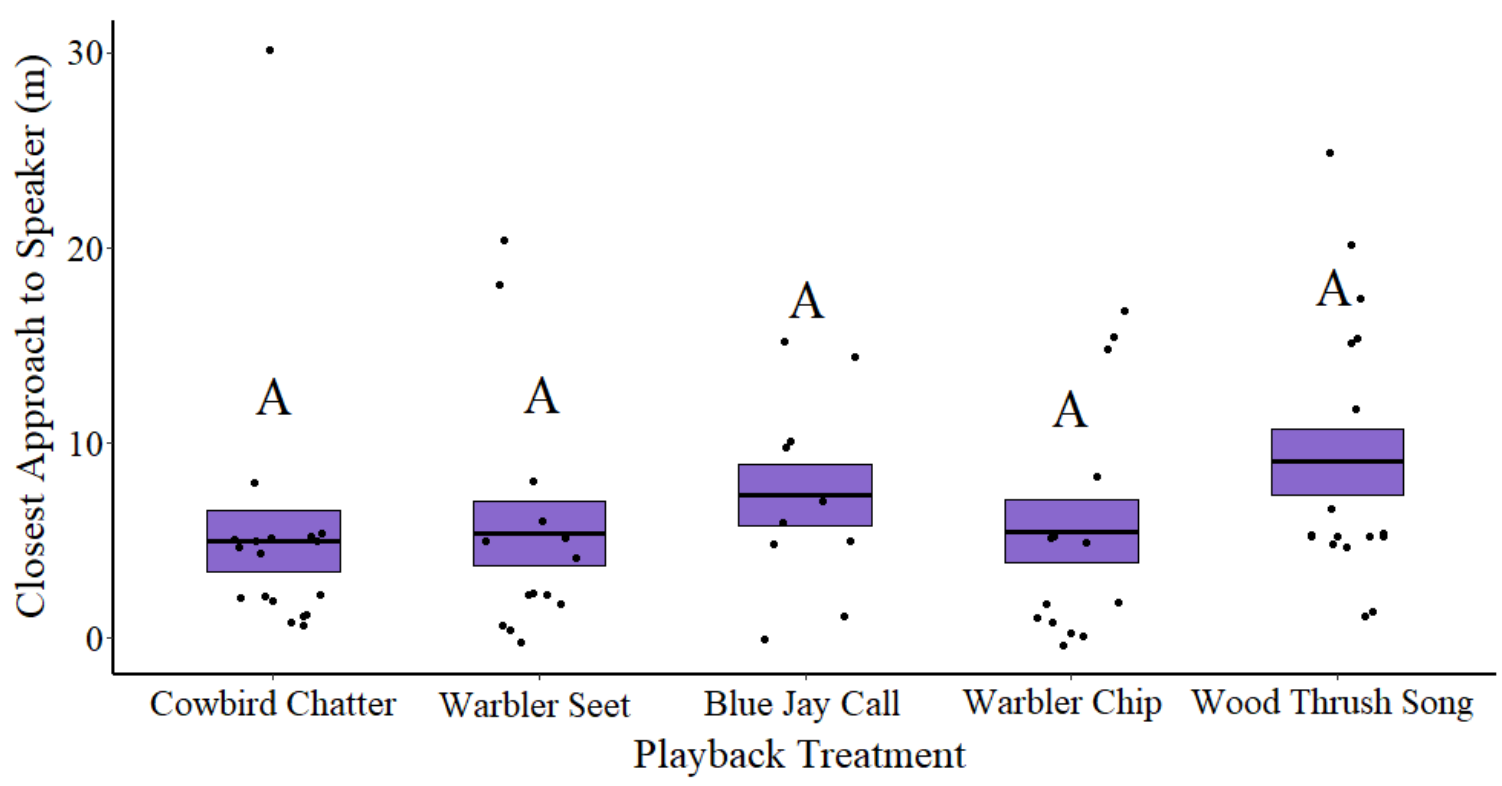

Note. Means are shown with the bold line, and shaded boxes represent standard errors. Boxes with the same letter denote no significant post hoc statistical differences between treatments.

\section{Nest Protection Behavior}

The majority of female warblers $(90 \%)$ with known nest locations returned to their nest sometime during the trial after hearing a seet call from the playback or their partner, or after producing a seet call themselves. We found that hearing or producing a seet significantly increased the probability of whether females returned quickly to the nest both within one minute of playback onset $(F(1,30)=11.27, p<.01$; $40 \%$ returned $)$, and within $3 \min (F(1,30)=6.28, p=.017 ; 80 \%$ returned $)$.

\section{Discussion}

Numerous published replication and pivoting experimental studies in the yellow warbler/brownheaded cowbird system have led to an integrated understanding of the seet call as a referential alarm call used in antiparasitic nest defense and the socio-environmental contexts that promote its use (see Appendix). Together with our recent works (Lawson et al., 2020, 2021), our study here is amongst the first to use solely acoustic stimuli to compare female yellow warblers' aggressive responses towards a full series of brood parasite, nest predator, and conspecific alarm vocalizations. Indeed, previous studies in this system used mostly either combinations of acoustic/visual stimuli or only visual stimuli. Results from our quasi-replication are highly consistent with those of past model presentation studies: female yellow warblers produced seet calls specifically in response to brood parasitic threats (both cowbird chatter and other seet calls), whereas chip calls were produced more generally in response to nest predators and intruding conspecifics. In turn, as reported before (see Appendix), upon hearing seets produced by playbacks, their mate, or themselves, female warblers predictably returned to sit upon their active nest with eggs.

Many of our results were similar to those of previous studies in this system, in that female host aggression responses varied depending on the nest threat at hand. Females responded swiftly to all experimental treatments relative to the control playback, though there was no difference in latency 
between experimental treatments. Female hosts produced seet calls only during cowbird chatter and conspecific seet call playbacks, adding further support to the specificity of the seet call and its use as a referential warning for a nearby brood parasitic threat (Evans et al., 1993; Gill \& Bierema, 2013). Another similarity to previous work was that a majority of female yellow warblers rushed back to and sat on their nests swiftly after hearing or producing seet calls, a key behavioral response reported in previous studies that defines the responses to seet calls as an adaptive, anti-parasitic nest defense behavior (Gill \& Bierema, 2013; Gill \& Sealy, 2004). We found that female hosts produced more chip calls during blue jay and chip call playbacks compared to all other treatment and control playbacks. Previous studies have characterized chips as calls produced primarily in response to general threats (predators of nests and/or nesting adults) and towards conspecifics that invade a territory (Gill \& Sealy, 1996: Hobson et al., 1988: Hobson \& Sealy, 1989b). In experimental studies that specifically compared responses to a cowbird versus a nest predator model, the nest predator model elicited more chip calls (Gill \& Sealy 1996, 2004: Kuehn et al., 2016), similar to the qualitative, but not statistically different, patterns seen in our study.

Our quasi-replication found some differences from previous studies, as well. Latency to respond had been used as a response metric only once before in Gill et al. (1997) who found that yellow warblers responded more quickly to female cowbird models compared to male or control models. In our study, females responded more swiftly to playbacks of cowbird chatters, seet calls, chip calls, and blue jay calls compared to control wood thrush songs, though there was no statistical difference in latency between the non-control treatments. For the response metric of closest approach, we found no statistical difference between experimental treatments, in that female yellow warblers approached all playbacks similarly close. This is distinct from the findings of Gill and Sealy (1996) who found that females approached the experimental models more closely than the control, and in particular, the cowbird model more closely than the nest predator common grackle (Quiscalus quiscula) model (also see Gill et al., 1997 for similar results with morphologically modified cowbird models). The use of acoustic playback presentation alone generates no visual target for responding subjects to home in on, which may result in different findings for closest approach compared to model presentation studies.

In our study, there were a number of chatter call playback trials $(\sim 50 \%)$ where live female cowbirds naturally approached the playback, possibly influencing the female yellow warblers' seet calling and nest return responses. However, cowbird presence during cowbird playbacks did not statistically covary with whether warblers seet called in response to the chatter playback (Fisher's exact test, $p=.37$ ), indicating that cowbird chatters, like cowbird models, are a suitable stimulus to experimentally simulate cowbirds. Female warblers seet called equally during cowbird chatter playbacks than during seet playbacks, but in our playback study with male yellow warblers (Lawson et al., 2021), we found that males seet called at a higher rate towards cowbird chatters compared to seet call playbacks. Personal (private) information (sensu Thorogood \& Davies, 2012) about brood parasitism risk, such as directly seeing or hearing the brood parasite, can offer greater reliability of the threat compared to social information obtained from assessing cowbird presence based on seet calls from neighbors. Additionally, the role of personal versus social information has also been recorded in other alarm-calling species in response to predation risk (e.g., Carlson et al., 2020). Stronger responses to social information of the seet call by female yellow warblers in comparison to males may be because females primarily stay hidden when incubating the nest, and thus may be more dependent on information about cowbird risk from others.

Future studies could expand on whether stimulus modality (visual vs. acoustic) affects the magnitude of alarm calling and other behavioral responses towards the threat, and if this varies with nest stage or sex of the target subject. Studies could also be conducted to compare responses of experienced ( $2+$ years old) and inexperienced breeder ( 1 year old) yellow warbler females to various playbacks, as first year yellow warblers of both sexes can be reliably aged in the spring (Pyle, 1997). Hobson and Sealy (1989a) presented cowbird models to female yellow warblers of varying ages and found that older warblers responded more aggressively to the model, which suggests that long-term prior personal experience plays a role in response to brood parasitic cowbirds. 
Our results demonstrate the importance of both replication and refinement of methodology in stimulus presentation studies meant to elicit specific behaviors, including alarm calls. The referential function of the yellow warbler's seet call and the specific contexts in which it is produced has become known through a series of replication and pivoting studies aimed at an increasingly better understanding of its use as an anti-parasitic alarm call. Our study further supports the yellow warbler's seet calls' role as a functionally referent signal to alert about brood parasitism risks near host nests (see Appendix; also see Lawson et al., 2020 for its use in heterospecific communication systems), whereas the chip call serves as a generic anti-predatory alarm call. We conclude anew that acoustic stimuli of both cowbirds and nest predators are sufficient to elicit yellow warbler seet and chip calls, respectively, but the magnitude of some behavioral responses may vary depending on the sensory modality of the presentation stimulus used.

\section{Acknowledgements}

We are grateful to the Champaign County Forest Preserve District, the Vermilion County Conservation District, the Illinois Department of Natural Resources, the US Fish and Wildlife Service, and the University of Illinois Animal Ethics Committee for permitting us to conduct this research. We thank Becky Fuller, TJ Benson, Nick Antonson, Hannah Scharf, Sarah Winnicki, and others for assistance with statistics. The project was funded by the American Ornithological Society (to SLL), the Illinois Ornithological Society (to SLL), the National Geographic Society (NGS-60453R-19 to MEH), the School of Integrative Biology (Clark Research Support Grant, Lebus Fund Award, Dissertation Travel Grant to SLL) at the University of Illinois/Urbana-Champaign, the Hanse-Wissenschaftskolleg, Germany (to $\mathrm{MEH}$ ), and the USA National Science Foundation (IOS \# 1952726 to SAG and IOS \#1953226 to MEH).

\section{References}

Blackburn, T. M., Su, S., \& Cassey, P. (2014). A potential metric of the attractiveness of bird song to humans. Ethology, 120, 305-312.

Briskie, J. V, Sealy, S. G., \& Hobson, K. A. (1992). Behavioral defenses against avian brood parasitism in sympatric and allopatric host populations. Evolution, 46, 334-340.

Burgham, M. C. J., \& Picman, J. (1989). Effect of brown-headed cowbirds on the evolution of yellow warbler antiparasite strategies. Animal Behaviour, 38, 298-308.

Campobello, D., \& Sealy, S. G. (2011). Nest defence against avian brood parasites is promoted by egg-removal events in a cowbird-host system. Animal Behaviour, 82, 885-891.

Carlson, N., Greene, E., \& Templeton., C. N. (2020). Nuthatches vary their alarm calls based upon the source of the eavesdropped signals. Nature Communications, 11, 526.

Chuang-Dobbs, H. C., Webster, M. S., \& Holmes, R. T. (2001). The effectiveness of mate guarding by male blackthroated blue warblers. Behavioral Ecology, 12, 541-546.

Davies, N. B. (2010). Cuckoos, cowbirds and other cheats. A\&C Black.

DellaSala, D. A. (1986). Polygyny in the yellow warbler. The Wilson Bulletin, 98, 152-154

Evans, C. S., Evans, L, \& Marler, P. (1993). On the meaning of alarm calls: Functional reference in an avian vocal system. Animal Behaviour, 46, 23-38.

Ficken, M. S., \& Ficken, R. W. (1965). Comparative ethology of the chestnut-sided warbler, yellow warbler, and american redstart. The Wilson Bulletin, 77, 363-375.

Folkers, K. L., \& Lowther, P. E. (1985). Responses of nesting red-winged blackbirds and yellow warblers to brownheaded cowbirds. Journal of Field Ornithology, 56, 175-177.

Gill, S. A., \& Bierema, A. M. K. (2013). On the meaning of alarm calls: A review of functional reference in avian alarm calling. Ethology, 119, 449-461.

Gill, S. A., Grieef, P. M., Staib, L., M., \& Sealy, S. G. (1997). Does nest defence deter or facilitate cowbird parasitism? A test of the nesting-cue hypothesis. Ethology, 103, 56-71.

Gill, S. A., Neudorf, D. L. H, \& Sealy, S. G. (1997). Host responses to cowbirds near the nest: Cues for recognition. Animal Behaviour, 53, 1287-1293.

Gill, S. A., Neudorf, D. L. H., \& Sealy, S. G. (2008). Do hosts discriminate between sexually dichromatic male and 
female brown-headed cowbirds? Ethology, 114, 548-556.

Gill, S. A., \& Sealy, S. G. (1996). Nest defence by yellow warblers: Recognition of a brood parasite and an avian nest predator. Behaviour, 133, 263-282.

Gill, S. A., \& Sealy, S. G. (2003). Tests of two functions of alarm calls given by yellow warblers during nest defence. Canadian Journal of Zoology, 81, 1685-1690.

Gill, S. A., \& Sealy, S. G. (2004). Functional reference in an alarm signal given during nest defence: Seet calls of yellow warblers denote brood-parasitic brown-headed cowbirds. Behavioral Ecology and Sociobiology, 56, 71-80.

Guigueno, M. F., \& Sealy, S. G. (2011). Aggression towards egg-removing cowbird elicits clutch abandonment in parasitized yellow warblers, Dendroica petechia. Animal Behaviour, 81, 211-218.

Hobson, K. A., Bouchart, M. L., \& Sealy, S. G. (1988). Responses of naive yellow warblers to a novel nest predator. Animal Behaviour, 36, 1823-1830.

Hobson, K. A., \& Sealy, S. G. (1989a). Responses of yellow warblers to the threat of cowbird parasitism. Animal Behaviour, 38, 510-519.

Hobson, K. A., \& Sealy, S. G. (1989b). Mate guarding in the yellow warbler Dendroica petechia. Ornis Scandinavica, 20, 241-249.

Kelly, J. K. (2017). Testing proximate causes and ultimate explanations of social cue use for habitat selection by songbirds. Unpublished doctoral disseration. University of Illinois Urbana-Champaign.

Kelly, J. K., Chiavacci, S. J., Benson, T. J., \& Ward, M. P. (2018). Who is in the neighborhood? Conspecific and heterospecific responses to perceived density for breeding habitat selection. Ethology, 124, 269-278.

Kelly, J. K., Suckow, N. M., \& Ward, M. P. (2019). Preferential settling at sites with higher conspecific density does not protect yellow warblers (Setophaga petechia) from brood parasitism. Acta Oecologica, 96, 24-28.

Kendeigh, S. C. (1941). Birds of a prairie community. The Condor, 43, 165-174.

Kroodsma, D. E., Byers, B. E., Goodale, E., Johnson, S., \& Liu, W.-C. (2001). Pseudoreplication in playback experiments, revisited a decade later. Animal Behaviour, 61, 1029-1033.

Kuehn, M. J., Peer, B. D., Mccleery, R. A., \& Rothstein, S. I. (2016). Yellow warbler defenses are retained in the absence of brood parasitism but enhanced by experience with cowbirds. Behavioral Ecology, 27, 279-286.

Lawson, S. L., Enos, J. K., Mendes, N. C., Gill, S. A., \& Hauber, M. E. (2020). Heterospecific eavesdropping on an anti-parasitic referential alarm call. Communications Biology, 3, 143.

Lawson, S. L., Enos, J. K., Mendes, N. C., Gill, S. A., \& Hauber, M. E. (2021). Pairing status moderates both the production of and responses to anti-parasitic referential alarm calls in male yellow warblers. Ethology, 127, 385-394.

Marshall, J., \& Balda, R. P. (1974). The breeding ecology of the painted redstart. The Condor, 76, 89-101.

Merrill, L., Chiavacci, S. J., Paitz, R. T., \& Benson, T. J. (2017). Rates of parasitism, but not allocation of egg resources, vary among and within hosts of a generalist avian brood parasite. Oecologia, 184, 399-410.

Mitra, S. S. (1999). Ecology and behavior of yellow warblers breeding in Rhode Island's great swamp. Northeastern Naturalist, 6, 249-262.

Pyle, P. (1997). Identification guide to North American birds: A compendium of information on identifying, ageing, and sexing "near-passerines" and passerines in the hand. Slate Creek Press.

Robertson, R. J., \& Norman, R. F. (1976a). Behavioral defenses to brood parasitism by potential hosts of the brownheaded cowbird. The Condor, 78, 166-173.

Robertson, R. J., \& Norman, R. F. (1976b). The function and evolution of aggressive host behavior towards the brown-headed cowbird (Molothrus ater). Canadian Journal of Zoology, 55, 508-518.

Sealy, S. G., Neudorf, D. L., Hobson, K. A., \& Gill, S.A. (1998). Nest defense by potential hosts of the Brownheaded Cowbird: Methodological approaches, benefits of defense, and coevolution. In S. I. Rothstein \& S. K. Robinson (Eds.), Parasitic birds and their hosts (pp. 194-211). Oxford University Press.

Stutchbury, B. J., Rhymer, J. M., \& Morton, E. S. (1994). Extrapair paternity in hooded warblers. Behavioral Ecology, 5, 384-391.

Thorogood, R., \& Davies, N. B. (2012). Cuckoos combat socially transmitted defenses of Reed Warbler hosts with a plumage polymorphism. Scientific Reports, 337, 578-580.

Toms, J. T. (2012). Behavior suggests that Adelaide's warblers Setophaga adelaidae are not sexually monogamous. Journal of Caribbean Ornithology, 25, 77-82. 


\section{Appendix}

Studies Involving Yellow Warbler Responses to Brown-headed Cowbird Presentations

\begin{tabular}{|c|c|c|c|c|c|c|c|}
\hline Citation & $\begin{array}{c}\text { Parasite stimuli } \\
\text { presented }\end{array}$ & $\begin{array}{c}\text { Predator stimuli } \\
\text { presented } \\
\text { (if any) } \\
\end{array}$ & $\begin{array}{c}\text { Control presented } \\
\text { (if any) }\end{array}$ & Nest Stage & $\begin{array}{l}\text { Sympatry } \\
\text { or allopatry }\end{array}$ & $\begin{array}{c}\text { Yellow } \\
\text { warbler } \\
\text { subjects } \\
\end{array}$ & Behaviors measured \\
\hline $\begin{array}{l}\text { Robertson \& } \\
\text { Norman (1976) }\end{array}$ & $\begin{array}{l}\text { Female or male } \\
\text { cowbird model (in } \\
\text { bowed or standing } \\
\text { position) }\end{array}$ & None & $\begin{array}{l}\text { One of three models: } \\
\text { song sparrow, savannah } \\
\text { sparrow or house sparrow }\end{array}$ & $\begin{array}{l}\text { Laying and } \\
\text { incubation }\end{array}$ & Sympatry & $\begin{array}{l}\text { Adult males } \\
\text { and females }\end{array}$ & $\begin{array}{l}\text { Alarm calls, hovering, } \\
\text { distraction displays, distance to } \\
\text { model, strikes }\end{array}$ \\
\hline $\begin{array}{l}\text { Robertson \& } \\
\text { Norman (1977) }\end{array}$ & $\begin{array}{l}\text { Female cowbird model, } \\
\text { Male cowbird model }\end{array}$ & None & $\begin{array}{l}\text { One of three models: } \\
\text { song sparrow, savannah } \\
\text { sparrow or house sparrow }\end{array}$ & Laying & Sympatry & $\begin{array}{l}\text { Adult males } \\
\text { and females }\end{array}$ & $\begin{array}{l}\text { Alarm calls, hovering, } \\
\text { distraction displays, distance to } \\
\text { model, strikes }\end{array}$ \\
\hline $\begin{array}{l}\text { Folkers \& } \\
\text { Lowther (1985) }\end{array}$ & Female cowbird model & None & Fox sparrow model & $\begin{array}{l}\text { Laying and } \\
\text { incubation }\end{array}$ & Sympatry & $\begin{array}{l}\text { Adult males } \\
\text { and females }\end{array}$ & $\begin{array}{l}\text { Alarm calls, hovering, } \\
\text { distraction displays, distance to } \\
\text { model, strikes }\end{array}$ \\
\hline $\begin{array}{l}\text { Burgham \& } \\
\text { Picman (1989) }\end{array}$ & $\begin{array}{l}\text { Female cowbird model, } \\
\text { Male cowbird model }\end{array}$ & $\begin{array}{l}\text { Crow model (nest } \\
\text { predator) }\end{array}$ & House sparrow model & $\begin{array}{l}\text { Laying, } \\
\text { incubation, } \\
\text { nestling }\end{array}$ & $\begin{array}{l}\text { Recent } \\
\text { sympatry }\end{array}$ & $\begin{array}{l}\text { Adult males } \\
\text { and females }\end{array}$ & $\begin{array}{l}\text { Alarm calls, distance to model, } \\
\text { distraction displays, hovering, } \\
\text { strikes }\end{array}$ \\
\hline $\begin{array}{l}\text { Hobson \& Sealy } \\
\text { (1989a) }\end{array}$ & Female cowbird model & None & Fox sparrow model & $\begin{array}{l}\text { Building, } \\
\text { laying, } \\
\text { incubation and } \\
\text { nestling }\end{array}$ & Sympatry & $\begin{array}{l}\text { Adult males, } \\
\text { females either } \\
1 \text { year old or } \\
1+\text { years old }\end{array}$ & $\begin{array}{l}\text { Alarm calls, distance to model, } \\
\text { nest-protection behavior, } \\
\text { distraction displays, hovering, } \\
\text { strikes }\end{array}$ \\
\hline $\begin{array}{l}\text { Briskie et al. } \\
(1992)\end{array}$ & Female cowbird model & None & Fox sparrow model & Laying & $\begin{array}{l}\text { Sympatry } \\
\text { and } \\
\text { allopatry }\end{array}$ & Adult females & $\begin{array}{l}\text { Alarm calls, distance to model, } \\
\text { nest-protection behavior, } \\
\text { distraction displays, hovering, } \\
\text { strikes }\end{array}$ \\
\hline $\begin{array}{l}\text { Gill \& Sealy } \\
\text { (1996) }\end{array}$ & Female cowbird model & $\begin{array}{l}\text { Common grackle } \\
\text { model (nest predator) }\end{array}$ & Fox sparrow model & $\begin{array}{l}\text { Laying and } \\
\text { nestling }\end{array}$ & Sympatry & $\begin{array}{l}\text { Adult males } \\
\text { and females }\end{array}$ & $\begin{array}{l}\text { Distance to model, vocalizations, } \\
\text { chip calls, distraction displays, } \\
\text { close passes, hovering, strikes, } \\
\text { nest-protection behavior }\end{array}$ \\
\hline $\begin{array}{l}\text { Gill, Neudorf et } \\
\text { al. (1997) }\end{array}$ & Female cowbird model & $\begin{array}{l}\text { Female cowbird } \\
\text { model with modified } \\
\text { beak }\end{array}$ & None & Laying & Sympatry & Adult females & $\begin{array}{l}\text { Time spent within } 2 \mathrm{~m} \text { of model, } \\
\text { seet calls, chip calls, nest- } \\
\text { protection behavior, distraction } \\
\text { displays, strikes, latency }\end{array}$ \\
\hline
\end{tabular}


Lawson et al. 229

\begin{tabular}{|c|c|c|c|c|c|c|c|}
\hline Citation & $\begin{array}{c}\text { Parasite stimuli } \\
\text { presented }\end{array}$ & $\begin{array}{l}\text { Predator stimuli } \\
\text { presented } \\
\text { (if any) }\end{array}$ & $\begin{array}{l}\text { Control presented } \\
\text { (if any) }\end{array}$ & Nest Stage & $\begin{array}{l}\text { Sympatry } \\
\text { or allopatry }\end{array}$ & $\begin{array}{c}\text { Yellow } \\
\text { warbler } \\
\text { subjects }\end{array}$ & Behaviors measured \\
\hline $\begin{array}{l}\text { Gill, Neudorf et } \\
\text { al. (1997) }\end{array}$ & Female cowbird chatter & None & Male cowbird perched song & Laying & Sympatry & Adult females & See above \\
\hline $\begin{array}{l}\text { Gill, Grieef et al. } \\
\text { (1997) }\end{array}$ & Female cowbird model & None & None & Laying & Sympatry & $\begin{array}{l}\text { Adult males } \\
\text { and females }\end{array}$ & $\begin{array}{l}\text { Time spent different distances } \\
\text { from the model, close passes, } \\
\text { vocalizations, nest-protection } \\
\text { behavior, distraction displays, } \\
\text { hovers, strikes, perch changes }\end{array}$ \\
\hline $\begin{array}{l}\text { Gill \& Sealy } \\
\text { (2003) }\end{array}$ & Seet calls & Chip calls & None & $\begin{array}{l}\text { Laying and } \\
\text { nestling }\end{array}$ & Sympatry & $\begin{array}{l}\text { Adult males } \\
\text { and females }\end{array}$ & Seet calls, chip calls \\
\hline $\begin{array}{l}\text { Gill \& Sealy } \\
\text { (2004) }\end{array}$ & Female cowbird model & $\begin{array}{l}\text { Gray jay model (nest } \\
\text { predator) }\end{array}$ & Fox sparrow model & $\begin{array}{l}\text { Laying and } \\
\text { nestling }\end{array}$ & $\begin{array}{l}\text { Sympatry } \\
\text { and } \\
\text { allopatry }\end{array}$ & Adult females & $\begin{array}{l}\text { Seet calls, chip calls, nest- } \\
\text { protection behavior }\end{array}$ \\
\hline $\begin{array}{l}\text { Gill \& Sealy } \\
\text { (2004) }\end{array}$ & Seet calls & Chip calls & None & $\begin{array}{l}\text { Laying and } \\
\text { nestling }\end{array}$ & $\begin{array}{l}\text { Sympatry } \\
\text { and } \\
\text { allopatry }\end{array}$ & Adult females & $\begin{array}{l}\text { Seet calls, chip calls, nest- } \\
\text { protection behavior }\end{array}$ \\
\hline $\begin{array}{l}\text { Gill, Neudorf et } \\
\text { al. (2008) }\end{array}$ & Female cowbird & None & Fox sparrow model & $\begin{array}{l}\text { Laying and } \\
\text { nestling }\end{array}$ & Sympatry & $\begin{array}{l}\text { Adult males } \\
\text { and females }\end{array}$ & $\begin{array}{l}\text { Seet and chip calls, distraction } \\
\text { displays, nest-protection } \\
\text { behavior }\end{array}$ \\
\hline $\begin{array}{l}\text { Campobello \& } \\
\text { Sealy (2011) }\end{array}$ & $\begin{array}{l}\text { Female cowbird model, } \\
\text { two yellow warbler } \\
\text { models posed fighting a } \\
\text { female cowbird model } \\
\text { accompanied by seet } \\
\text { playback }\end{array}$ & $\begin{array}{l}\text { Female cowbird } \\
\text { model removing an } \\
\text { egg }\end{array}$ & Fox sparrow model & Laying & Sympatry & $\begin{array}{l}\text { Adult males } \\
\text { and females }\end{array}$ & $\begin{array}{l}\text { Seet calls, strikes, distraction } \\
\text { displays }\end{array}$ \\
\hline $\begin{array}{l}\text { Guigueno \& } \\
\text { Sealy (2011) }\end{array}$ & $\begin{array}{l}\text { Female cowbird model } \\
\text { in laying position }\end{array}$ & $\begin{array}{l}\text { Female cowbird } \\
\text { model removing an } \\
\text { egg }\end{array}$ & None & Laying & Sympatry & $\begin{array}{l}\text { Adult males } \\
\text { and females }\end{array}$ & Seet calls, chip calls, strikes \\
\hline $\begin{array}{l}\text { Kuehn et al. } \\
(2016)\end{array}$ & Female cowbird model & $\begin{array}{l}\text { One of two models: } \\
\text { Loggerhead shrike or } \\
\text { sharp-shinned hawk } \\
\text { (both general } \\
\text { predators) }\end{array}$ & $\begin{array}{l}\text { One of five models: male } \\
\text { western meadowlark, male } \\
\text { red-winged blackbird, } \\
\text { California towhee, European } \\
\text { starling, hermit thrush }\end{array}$ & Incubation & $\begin{array}{l}\text { Sympatry } \\
\text { and } \\
\text { allopatry }\end{array}$ & Adult females & $\begin{array}{l}\text { Seet calls, nest-protection } \\
\text { behavior }\end{array}$ \\
\hline
\end{tabular}


Lawson et al. 230

\begin{tabular}{|c|c|c|c|c|c|c|c|}
\hline Citation & $\begin{array}{c}\text { Parasite stimuli } \\
\text { presented }\end{array}$ & $\begin{array}{c}\text { Predator stimuli } \\
\text { presented } \\
\text { (if any) }\end{array}$ & $\begin{array}{c}\text { Control presented } \\
\text { (if any) }\end{array}$ & Nest Stage & $\begin{array}{c}\text { Sympatry } \\
\text { or allopatry }\end{array}$ & $\begin{array}{c}\text { Yellow } \\
\text { warbler } \\
\text { subjects } \\
\end{array}$ & Behaviors measured \\
\hline $\begin{array}{l}\text { Kelly et al. } \\
(2019)\end{array}$ & $\begin{array}{l}\text { Female cowbird model } \\
\text { accompanied by chatter } \\
\text { calls }\end{array}$ & none & $\begin{array}{l}\text { Wood thrush model } \\
\text { accompanied by male song }\end{array}$ & $\begin{array}{l}\text { Stage not } \\
\text { determined }\end{array}$ & Sympatry & $\begin{array}{l}\text { Adult males } \\
\text { and females }\end{array}$ & $\begin{array}{l}\text { Number of warblers within } 30 \mathrm{~m} \\
\text { of model, seet calls }\end{array}$ \\
\hline $\begin{array}{l}\text { Lawson et al. } \\
(2021)\end{array}$ & Female cowbird chatter & Blue jay calls & Wood thrush song & Incubation & Sympatry & $\begin{array}{l}\text { Adult males } \\
\text { split into } \\
\text { paired and } \\
\text { unpaired }\end{array}$ & $\begin{array}{l}\text { Seet calls, chip calls, latency, } \\
\text { closest approach to speaker }\end{array}$ \\
\hline
\end{tabular}

